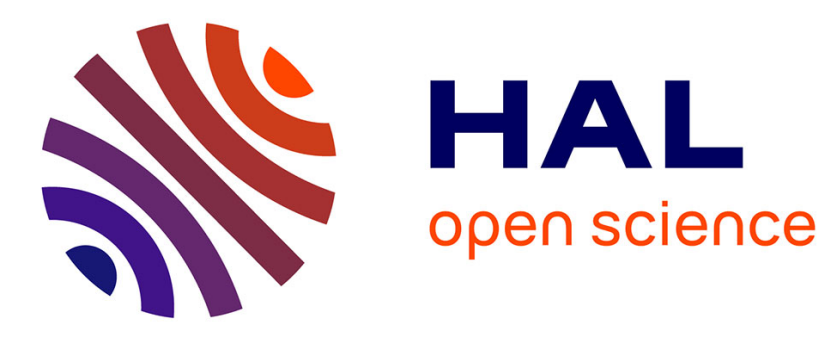

\title{
Flash Catalytic Pyrolysis of Polyethylene over (Alumino)silicate Materials
}

Sophie Klaimy, Carmen Ciotonea, Jérémy Dhainaut, Sébastien Royer, Mathilde Casetta, Sophie Duquesne, Grégory Tricot, Jean-françois Lamonier

\section{- To cite this version:}

Sophie Klaimy, Carmen Ciotonea, Jérémy Dhainaut, Sébastien Royer, Mathilde Casetta, et al.. Flash Catalytic Pyrolysis of Polyethylene over (Alumino)silicate Materials. ChemCatChem, 2019, 12 (4), pp.1109-1116. 10.1002/cctc.201901819 . hal-02998808

\section{HAL Id: hal-02998808 https://hal.science/hal-02998808}

Submitted on 10 Nov 2020

HAL is a multi-disciplinary open access archive for the deposit and dissemination of scientific research documents, whether they are published or not. The documents may come from teaching and research institutions in France or abroad, or from public or private research centers.
L'archive ouverte pluridisciplinaire HAL, est destinée au dépôt et à la diffusion de documents scientifiques de niveau recherche, publiés ou non, émanant des établissements d'enseignement et de recherche français ou étrangers, des laboratoires publics ou privés. 


\section{Heterogeneous \& Homogeneous \& Bio- \& Nano-}

\section{CATALYSIS}

\section{Accepted Article}

Title: Flash catalytic pyrolysis of polyethylene over (alumino)silicate materials

Authors: Sophie Klaimy, Carmen Ciotonea, Jérémy Dhainaut, Sébastien Royer, Mathilde Casetta, Sophie Duquesne, Grégory Tricot, and Jean-François Lamonier

This manuscript has been accepted after peer review and appears as an Accepted Article online prior to editing, proofing, and formal publication of the final Version of Record (VoR). This work is currently citable by using the Digital Object Identifier (DOI) given below. The VoR will be published online in Early View as soon as possible and may be different to this Accepted Article as a result of editing. Readers should obtain the VoR from the journal website shown below when it is published to ensure accuracy of information. The authors are responsible for the content of this Accepted Article.

To be cited as: ChemCatChem 10.1002/cctc.201901819

Link to VoR: http://dx.doi.org/10.1002/cctc.201901819 


\title{
Flash catalytic pyrolysis of polyethylene over (alumino)silicate materials
}

\author{
Sophie Klaimy, ${ }^{[a, b]}$, Carmen Ciotonea ${ }^{[a]}$, Jérémy Dhainaut ${ }^{[a]}$, Sébastien Royer ${ }^{[a]}$, Mathilde Casetta ${ }^{[b]}$, \\ Sophie Duquesne ${ }^{[\mathrm{b}]}$, Grégory Tricot ${ }^{[\mathrm{c}]}$ and Jean-François Lamonier*[a]
}

\begin{abstract}
A series of amorphous and crystalline (alumino)silicate catalysts, with variable acidity, are evaluated for the flash pyrolysis of polyethylene (PE). Catalysts morphology, acidity as well as textural properties are influencing the process of decomposition of PE. Incomplete PE conversion and significant wax formation are obtained under the reaction condition with pure amorphous and MFI-type silica. Complete conversion, and limited formation of wax, are observed with amorphous and MFI-type Si-Al containing catalyst. Acidity has a significant influence on the molecule size and nature. Then, the increase of the catalyst acidity leads to the decrease of the molecular weight of pyrolysis products and the increase of the gas and the light liquid fractions. In addition, the acidity increase promotes cyclization reaction, resulting in the increase of the cycled hydrocarbon/aromatic proportion in the liquid fraction. Then, from PE catalytic pyrolysis, up to $25 \mathrm{wt} \%$ of aromatics can be obtained in the liquid fraction with Si/AI ZSM-5 zeolite, while olefins remain the major fraction with the less acidic amorphous aluminosilicate catalyst.
\end{abstract}

\section{Introduction}

There has been an over-increasing demand for plastics during the past 50 years due to their versatile uses, low cost and fabrication capabilities, resulting in an always increasing amount of plastic waste generated [1]. Plastic waste has very low biodegradability and requires multiple costly steps namely sorting, washing, grinding and extrusion, for its effective recycling, arising worrisome environmental, social and economic issues. Therefore, it is urgent to find and implement effective and cheaper solutions for the reduction, reconditioning or recycling of the plastic waste [2].

Among the various processes to valorize the plastic waste, the thermal pyrolysis under neutral gas results in a wide distribution of products among them being highly valuable molecules such as aromatics or alkanes [3]. In the absence of oxygen, the thermal decomposition of polymers and of polyolefins more

[a] S. Klaimy, Dr. C. Ciotonea, Dr. J. Dhainaut, Prof. S. Royer. Prof. J.F. Lamonier, Univ. Lille, CNRS, Centrale Lille, ENSCL, Univ. Artois, UMR 8181 - UCCS - Unité de Catalyse et Chimie du Solide, F59000 Lille, France

E-mail: jean-francois.lamonier@univ-lille.fr

[b] S. Klaimy, Dr. M. Casetta, Prof. S. Duquesne, Univ. Lille, CNRS, INRA, ENSCL, UMR 8207-UMET-Unité Materiaux et Transformation, F-59000, Lille, France.

[c] Dr. G. Tricot, Univ. Lille, CNRS, UMR 8516 - LASIR - Laboratoire de Spectrochimie Infrarouge et Raman, F-59000 Lille, France Supporting information for this article is given via a link at the end of the document precisely occurs following a complex mechanism involving the formation of free radicals from the random scission of polymer chains [4]. The radical formation can be observed by ESR analysis of pyrolysed samples [4c,d]. The thermal pyrolysis results in the production of three different families of products can be used as fuels and/or sources of chemicals: C1 to C3 gases, liquid hydrocarbons and solid residue [5]. The proportion and composition of the three phases are dependent on reaction parameters such as the temperature and pressure applied, and the type of plastic waste used in the pyrolysis process [6]. While high amounts of plastic waste can be treated following this process, the required high temperature and costs associated to steps of separation refrain the large scale development of the process [7].

To address these drawbacks, catalysts are frequently used in combination with the pyrolysis process, resulting in the decreasing of the temperature necessary for the decomposition of the polymers. Moreover, catalysts are known for their ability to activate and orientate the chemical transformation of polymers [8]. This ability is strongly linked to the catalyst properties, which can be finely tailored depending on the application [9]. In catalytic pyrolysis (or pyrocatalysis), the morphology, the composition as well as the structural and textural properties of the catalysts, all have a notable influence on the conversion mechanism [10]. Therefore, even for simplified plastic waste feeds, such as pure polyethylene, the control and orientation toward selected molecules is challenging and requires a good knowledge of all the parameters involved, regarding the reaction process, but also from the point of view of the catalyst properties.

In the literature, a wide variety of heterogeneous catalysts have been reported for catalytic pyrolysis and among them are conventional solid acids such as zeolites, silica-alumina and alumina, but also mesostructured catalysts such as Al-MCM-41 $[10,11]$. Indeed, the acidity of the catalyst is an important parameter to consider in pyrolysis. In particular, it has been shown that, in the pyrolysis reaction of polystyrene, the surface acidity of the catalyst can be related to the increasing number of initiation sites for the pyrolysis reaction [5]. In this regard, acid catalysts allow to produce higher liquid yields (C5-C9), owing to the breaking of C-C bonds with preferential chain length [11]. An increase in branched alkanes and aromatics has also been observed, while the decomposition temperature and activation energies of decomposition are decreased by comparison with the thermal pyrolysis process [12]. Different mechanisms have been proposed, in which the decomposition of polymers (including polyethylene) follows an ionic mechanism, with the abstraction of the hydride ion occurring over Lewis acid sites, 
and the protonation of olefins formed by thermal decomposition over Brønsted acid sites [13].

Therefore, to achieve a high selectivity in liquid products over the final products of catalytic pyrolysis, the strength (strong and weak), the nature (Lewis or Brønsted and their ratio), and the location of the acid sites have to be finely controlled during the formulation of the catalyst [12]. The ZSM-5 zeolites (MFI-type) are by far the most used in the pyrolysis process. This is related to the combination of favorable features, in particular a good thermal stability and an adjustable acidity (through the silicium over aluminum ratio). Commercial ZSM-5 zeolites are frequently used for studies, but the reported performances do not afford the establishment of clear correlation between catalyst characteristics and product selectivities obtained by pyrocatalysis. This is related to the use of ZSM-5 coming from different suppliers or batches having, in most of the cases, even for comparable acidity, different physical properties [10a,15]. Another important parameter is indeed the catalyst porosity, controlling accessibility of the reactants to the internal active sites and diffusion of products. In the case of zeolites, more than $90 \%$ of the acidic sites are located within the crystals and are therefore only accessible through sub-nanometer porosity [16]. The catalytic pyrolysis is then deemed to occur mostly at the surface of the crystals. Other effective catalysts are silicaalumina [17]. Silica-alumina has the advantage of presenting not only acid sites but also larger pore sizes than zeolites. Consequently, during the decomposition process, in a first step larger molecules are cracked to smaller molecules by a primary reaction, leading to the diffusion of these molecules within the pores of the catalyst where further reactions can proceed leading to the production of non-aromatic products. Considering the lower acidity developed by amorphous silica-alumina, limited cracking occurs, and isomerization is promoted [18]. This work describes the polyethylene (PE) conversion over (alumino)silica catalysts under Flash Catalytic Pyrolysis conditions with the objective to discriminate the role of catalyst main properties (acidity, specific area, particle size and pore size distribution) on the product distribution and liquid product characteristics. Compared to classical (catalytic) pyrolysis process, flash (catalytic) pyrolysis is characterized by a high heating rate and short residence time of products at high temperature, conditions affording to maintain high liquid yields [19]. Materials synthesized include silicic and aluminosilicic MFI-type zeolites (Silicalite-1 and ZSM-5), in addition to amorphous $\mathrm{SiO}_{2}$ and silica-alumina. The results demonstrate the interest of the process for the recycling of plastic waste, with the possibility, varying the catalyst properties, to orientate reaction from paraffin-olefin to cycled hydrocarbon-aromatic.

\section{Results and Discussion}

\section{Characterization of catalysts}

X-ray diffractograms of the synthetized materials are shown in Figure 1(a). Si-MFI and Si/Al-MFI show the typical reflections of MFI structure by comparison with the JCPDS pdf file \# 44-003. The absence of a broad peak at $2 \theta=20-25^{\circ}$ confirms the production of highly crystalline materials even after the ionic exchange for the Al-rich zeolite for counter-ion exchange. For $\mathrm{Si}-\mathrm{MFI}$, the presence of low quantity of quartz phase is evidenced by the presence of a peak at $2 \theta$ of $22^{\circ}$ (Figure S1). Quartz formation is associated with the harsh conditions applied for the synthesis (high temperature and long period of hydrothermal treatment) [20]. The XRD pattern of $\mathrm{Si} / \mathrm{Al}$ and $\mathrm{SiO}_{2}$ (not shown) exhibits only a broad signal in the $2 \theta$ range $20-25^{\circ}$ which is characteristic of amorphous silica [11].

Figure 1 (b) presents the $\mathrm{N}_{2}$ physisorption isotherms of materials. The isotherms registered over the MFI zeolites are characterized by a well-defined plateau, according to Type I shape of the IUPAC classification. A sharp adsorption step occurs at low relative pressures $\left(P / P_{0}<0.1\right)$ which is indicative of the formation of a microporous material. For both amorphous materials $\left(\mathrm{SiO}_{2}\right.$ and $\left.\mathrm{Si} / \mathrm{Al}\right)$, the registered isotherms are of Type IV, which is classically encountered for porous materials with broad pore size distribution in the mesopore domain [14].
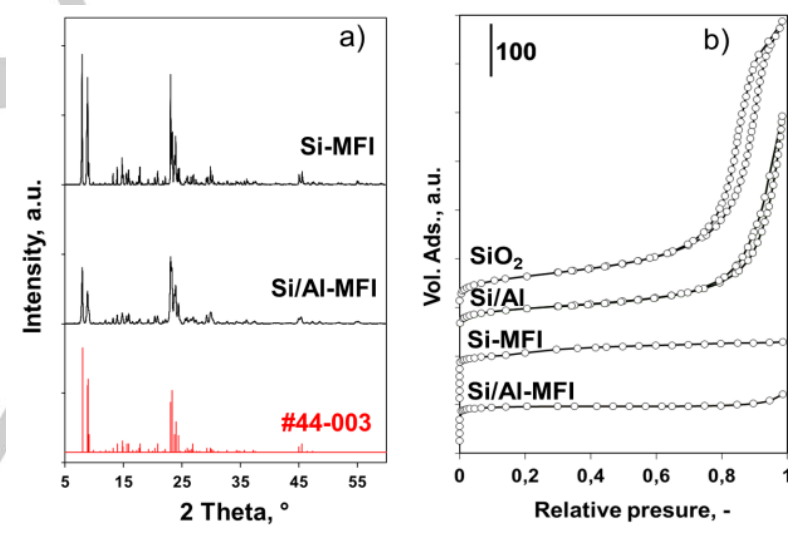

Figure 1. (a) XRD patterns for Si-MFI and Si/AI-MFI materials (bottom: ZSM5 (MFI) reference, JCPDS pdf file \# 44-0003); (b): $\mathrm{N}_{2}$ physisorption obtained for $\mathrm{SiO}_{2}, \mathrm{Si} / \mathrm{Al}, \mathrm{Si}-\mathrm{MFI}$ and Si/AI-MFI.

Table 1. Textural properties for $\mathrm{SiO}_{2}$, Si/AI, Si-MFI and Si/AI-MFI materials.

\begin{tabular}{lllllll}
\hline & $\begin{array}{l}\mathrm{S}_{\mathrm{BET}}{ }^{[\mathrm{a}]} \\
\mathrm{m}^{2} \mathrm{~g}^{-1}\end{array}$ & $\begin{array}{l}\mathrm{S}_{\mu}{ }^{[\mathrm{b}]} \\
\mathrm{m}^{2} \mathrm{~g}^{-1}\end{array}$ & $\begin{array}{l}\mathrm{S}_{\mathrm{ext}}{ }^{[\mathrm{c}]} \\
\mathrm{m}^{2} \mathrm{~g}^{-1}\end{array}$ & $\begin{array}{l}\mathrm{V}_{\mathrm{p}}{ }^{[\mathrm{d}]} \\
\mathrm{cm}^{3} \mathrm{~g}^{-1}\end{array}$ & $\begin{array}{l}\mathrm{V}_{\mu}^{[\mathrm{e}]} \\
\mathrm{cm}^{3} \mathrm{~g}^{-1}\end{array}$ & $\begin{array}{l}\mathrm{D}_{\text {part }}{ }^{[\mathrm{f}]} \\
\mathrm{nm}\end{array}$ \\
\hline $\mathrm{SiO} 2$ & 240 & 18 & 222 & 0.69 & 0.01 & 60 \\
\hline $\mathrm{Si} / \mathrm{Al}$ & 161 & 20 & 140 & 0.48 & 0.01 & 70 \\
\hline $\mathrm{Si}$-MFI & 402 & 344 & 58 & 0.19 & 0.14 & 1780 \\
\hline
\end{tabular}

[a] B.E.T. surface area; [b], microporous surface area; [c] external surface area, [d] total pore volume; [e] micropore volume; [f] hydrodynamic diameter obtained by DLS measurement.

Textural properties are displayed in Table 1. BET specific surface areas of $387 \mathrm{~m}^{2} \cdot \mathrm{g}^{-1}$ and $402 \mathrm{~m}^{2} \cdot \mathrm{g}^{-1}$ for Si/Al-MFI and Si$\mathrm{MFI}$, respectively are obtained, with a major contribution from the micropores $\left(S_{\mu}\right.$ being $>85 \%$ of the total surface area). 
Besides, the value of the total pore volume is close to that of the microporous volume, confirming that most of the porosity of the solids is related to the micropore structure. In contrast, for both amorphous materials, the contribution of the microporous surface to the BET surface is negligible. Surface areas of 140 and $222 \mathrm{~m}^{2} \cdot \mathrm{g}^{-1}$ are obtained for $\mathrm{Si} / \mathrm{Al}$ and $\mathrm{SiO}_{2}$, respectively. When comparing silica or alumina-silica containing samples, the total pore volume developed by the amorphous materials is 4 times larger than that of the crystalline solids. On the contrary, the micropore volumes are 12 to 17 times larger for MFI-type materials than for amorphous solids (Table 1).

Figure 2 shows SEM images illustrating the differences of morphology between the two MFI samples. Si-MFI crystals present a coffin shape (Figure $2(a-b)$ ), which is typical for crystalline MFI materials [21]. The average object sizes measured from SEM images are around $3.8 \mu \mathrm{m}$ in length and $0.8 \mu \mathrm{m}$ in thickness showing the formation of a microcrystalline material. Interestingly, Si/AI-MFI is presenting a completely different morphology, described as raspberry-shaped particulates (Figures 2d, Figure S1(a-b)) [10a, 13]. The objects formed are of homogenous diameter, around $1 \mu \mathrm{m}$, and are composed of aggregated nanocrystals with an average size of 80-90 nm, as illustrated in the Figure S1(b). The nanocrystals are expected to form during the first step of the synthesis (corresponding to the seeds synthesis), while the second step of the synthesis results in their aggregation to the raspberrytype objects.
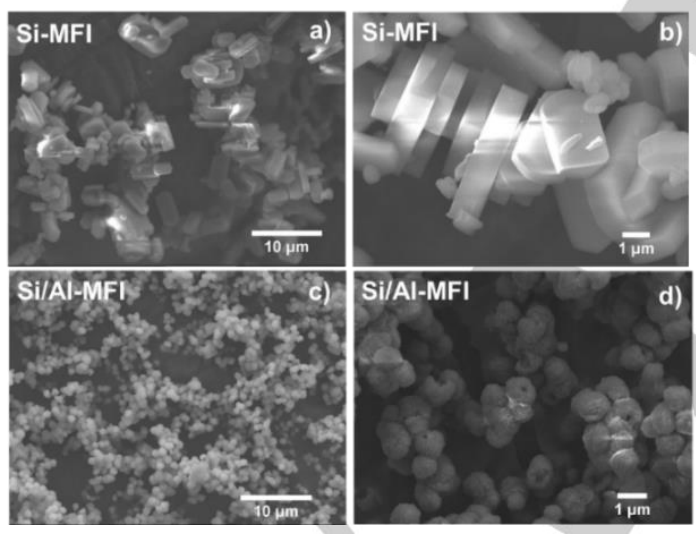

Figure 2. SEM images recorded for $\mathrm{SiO}_{2}, \mathrm{Si} / \mathrm{Al}, \mathrm{Si}-\mathrm{MFI}$ and $\mathrm{Si} / \mathrm{Al}-\mathrm{MFI}$ catalysts.

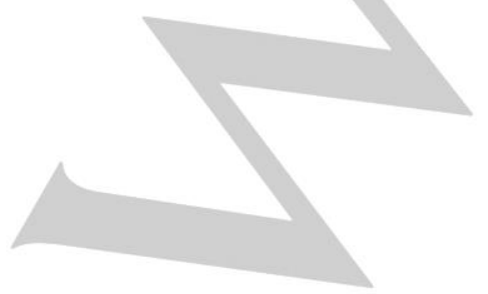

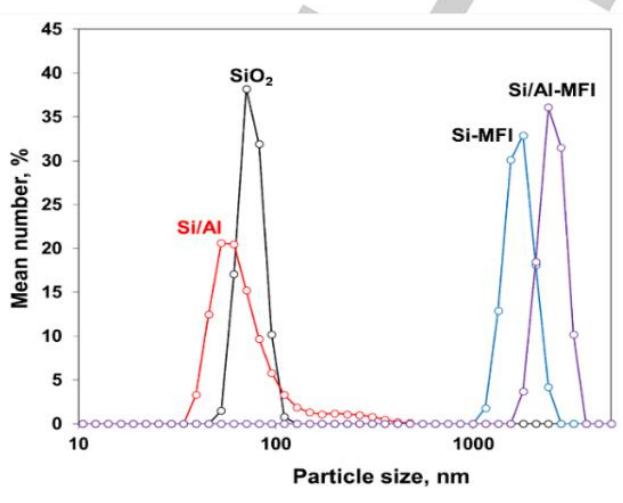

Figure 3. Particle size distribution obtained by DLS measurement for $\mathrm{SiO}_{2}$, Si/Al, Si-MFI and Si/Al-MFI materials.

DLS analysis was performed in order to determine the particle size distribution (Figure 3). The two MFI samples are showing large average diameter, with a maximum at $\sim 1800 \mathrm{~nm}$ for Si/AlMFI and $\sim 2400 \mathrm{~nm}$ for Si-MFI. These sizes are directly comparable with the average sizes of the objects observed in SEM images (Figure 2(b, d)). A sharper distribution is obtained for $\mathrm{SiO}_{2}$ and $\mathrm{Si} / \mathrm{Al}$ materials, with a maximum measured in the 60-70 nm interval. The particle size distribution obtained by DLS analysis is again in good agreement with the particle size observed on SEM images (Figures S3).

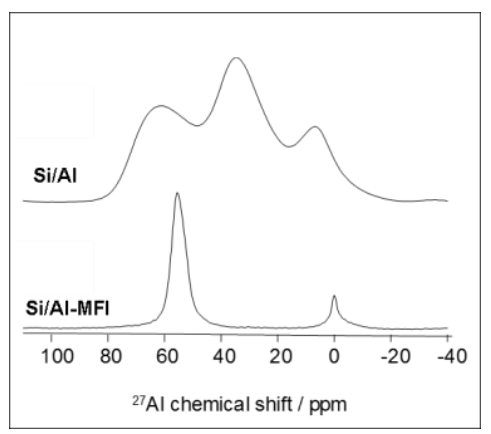

Figure 4. $1 \mathrm{D}^{27} \mathrm{Al}$ MAS-NMR spectra acquired at $18.8 \mathrm{~T}$ on the Si/Al and Si/AIMFI samples.

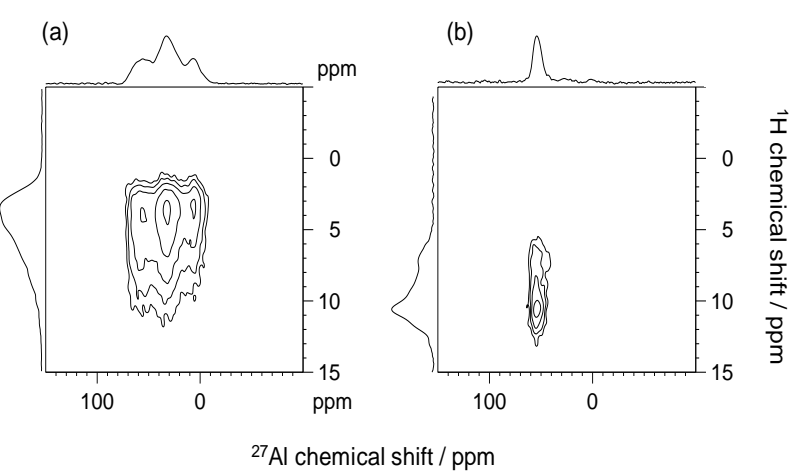


Figure 5. ${ }^{27} \mathrm{Al}\left({ }^{1} \mathrm{H}\right) \mathrm{D}$-HMQC spectra recorded at $18.8 \mathrm{~T}$ with a very short recoupling time of $200 \mu$ s on the $\mathrm{Si} / \mathrm{Al}$ (a) and Si/AI-MFI (b) samples. The 2D maps are accompanied by the ${ }^{27} \mathrm{Al}$ and ${ }^{1} \mathrm{H}$ projections in the horizontal and vertical axis.

Table 2. $\mathrm{NH}_{3}$-TPD analysis for the aluminosilicate materials.

\begin{tabular}{lccccc}
\hline Samples & \multicolumn{2}{c}{$\begin{array}{c}\text { Temperature } \\
\left({ }^{\circ} \mathrm{C}\right)\end{array}$} & & \multicolumn{3}{c}{$\begin{array}{c}\text { Acidity } \\
\left(\mathrm{mmol}^{[\mathrm{b}]} \mathrm{g}^{-1}\right)\end{array}$} & \\
\hline & $\begin{array}{l}\mathrm{LT} \\
\text { peak }\end{array}$ & $\begin{array}{c}\mathrm{HT} \\
\text { peak }\end{array}$ & $\begin{array}{c}\text { Total } \\
\text { acidity }\end{array}$ & $\begin{array}{c}\text { Weak } \\
\text { acidity }\end{array}$ & $\begin{array}{c}\text { Strong } \\
\text { acidity }\end{array}$ \\
\hline $\mathrm{SiO}_{2}$ & 340 & 465 & 0.045 & 0.030 & 0.015 \\
\hline $\mathrm{Si}-\mathrm{MFI}$ & 0 & 447 & 0.017 & - & 0.017 \\
\hline $\mathrm{Si} / \mathrm{Al}$ & 210 & & 0.209 & 0.071 & - \\
\hline Si/Al-MFI & 250 & & & 0.138 & \\
\hline
\end{tabular}

[a] temperature for $\mathrm{NH}_{3}$ desorption. [b] quantity of $\mathrm{NH}_{3}$ desorbed

$\mathrm{Si} / \mathrm{Al}$ and Si/Al-MFI samples were analyzed by ${ }^{27} \mathrm{Al}$ magic angle spinning nuclear magnetic resonance (MAS-NMR) (Figure 4) in order to assess the coordination state of aluminum atoms. The analysis performed on the Si/Al sample (Figure 4) presents three broad signals at 60,38 and $5 \mathrm{ppm}$ corresponding to aluminum in tetra-, penta- and octahedral coordination states, respectively. The signals broadness reveals a highly distributed chemical environment around the Al sites, which is in line with the amorphous structure of the Si/Al sample. The ${ }^{27} \mathrm{Al}$ MASNMR spectrum of the Si/AI-MFI sample (Figure 4) shows narrow peaks as expected from the crystalline structure and confirms the presence of tetra-coordinated framework aluminum (54 ppm) as the main Al species in the sample. The presence of extra-framework aluminum species in hexahedral coordination is evidenced by the peak at 0 ppm [22a]. Signal integration finally allows quantifying these two Al sites, with $90 \%$ of ${ }^{[4]} \mathrm{Al}$ and $10 \%{ }^{[6]} \mathrm{Al}$ species. Presence of $\mathrm{Al}-\mathrm{OH}$ linkages was then monitored with the editing of $2 \mathrm{D}{ }^{1} \mathrm{H} /{ }^{27} \mathrm{Al}$ correlation maps. As previously reported, the correlation signals observed here are signature of $\mathrm{Al}-\mathrm{OH}$ linkages owing to the very short recoupling time used in the pulse sequence [22b]. The $2 \mathrm{D}$ map recorded on the Si/Al sample indicates that the three Al species are involved in $\mathrm{Al}-\mathrm{OH}$ site but comparison between the 1D and the 2D Map 27Al projection (Figure 4, and horizontal axis of Figure 5a) suggests that ${ }^{[4]} \mathrm{Al}$ sites are less involved in the $\mathrm{Al} / \mathrm{H}$ interaction than the two higher coordination states. A single correlation signal can be observed in the $2 \mathrm{D}$ map acquired on the Si/Al-MFI sample showing the presence of ${ }^{[4]} \mathrm{Al}-\mathrm{O}-\mathrm{H}$ linkages. No signal involving the extra-framework ${ }^{[6]} \mathrm{Al}$ can be found in the 2D map but the low intensity of this signal has to be taken into account.

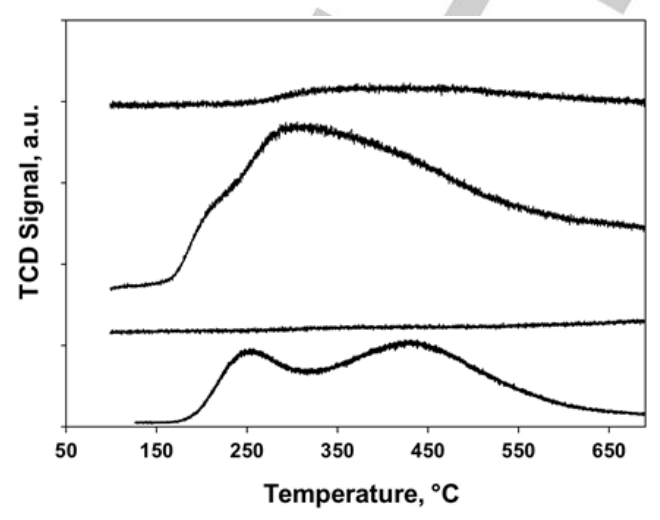

Figure 6. $\mathrm{NH}_{3}$-TPD profiles obtained for $\mathrm{SiO}_{2}$, Si/Al, Si-MFI and Si/Al-MFI. $\mathrm{Si} / \mathrm{Al}-\mathrm{MFI}$ TCD signal is divided by 100 for the sake of comparison.

Quantity (mmol.g-1 of desorbed $\mathrm{NH}_{3}$ ) and relative strength of the acid sites (temperature of $\mathrm{NH}_{3}$ desorption) were obtained by temperature programmed desorption of ammonia ( $\mathrm{NH}_{3}$-TPD). The $\mathrm{NH}_{3}$-TPD profiles are shown in Figure 6 and the corresponding quantitative information are provided in Table 2. Regardless of their structural and textural characteristics, the two pure silica materials, $\mathrm{SiO}_{2}$ and $\mathrm{Si}-\mathrm{MFI}$, have a low acidity, with a total quantity of $\mathrm{NH}_{3}$ desorbed below $0.05 \mathrm{mmol} . \mathrm{g}^{-1}$. These two materials are distinguished by the presence of a weak acidity for $\mathrm{SiO}_{2}$ which can be related to silanol presence on its external surface [22a]. As expected, the addition of aluminum to silica generates acidity. This extra acidity is related to (i) Brønsted acidity which resides in the bridging hydroxyl group originating from the replacement of $\mathrm{Si}^{4+}$ in the framework by $\mathrm{Al}^{3+}$ and (ii) Lewis acidity assigned to the presence of extraframework alumina species [22b]. Si/Al presents a total $\mathrm{NH}_{3}$ desorption of 0.209 mmol. $\mathrm{g}^{-1}$ mostly assigned to weak acidity with two desorption peaks located at $210^{\circ} \mathrm{C}$ and $290^{\circ} \mathrm{C}$. Si/AlMFI exhibits a much higher density of acid sites, characterized by a high total $\mathrm{NH}_{3}$ desorption of $0.638 \mathrm{mmol} . \mathrm{g}^{-1}$. Two $\mathrm{NH}_{3}$ desorption peaks are clearly distinguished (Figure 7). The first peak is centered at around $250{ }^{\circ} \mathrm{C}$ and corresponds to weak acidity $\left(0.193 \mathrm{mmol} . \mathrm{g}^{-1}\right)$, as observed for the Si/Al catalyst. The second peak is centered at around $420{ }^{\circ} \mathrm{C}$ and corresponds to strong acid sites $\left(0.445 \mathrm{mmol} . \mathrm{g}^{-1}\right)$. Such sites are not observed over Si/Al catalyst for which the second desorption occurs at a temperature $\sim 150{ }^{\circ} \mathrm{C}$ below.

\section{Pyrolysis of polyethylene}

\subsection{Thermogravimetric study of the decomposition}

Figure 7 shows the TG curves obtained during PE thermal and catalytic pyrolysis. In the case of PE thermal decomposition, the weight loss is observed to start at $420{ }^{\circ} \mathrm{C}$, with a complete decomposition observed at $502{ }^{\circ} \mathrm{C}$. The use of pure silica catalysts $\left(\mathrm{SiO}_{2}\right.$ and $\left.\mathrm{Si}-\mathrm{MFI}\right)$ lead to a decomposition of PE at a temperature identical to the thermal decomposition showing the complete inefficiency of these two solids as catalysts to promote the decomposition of PE at lower temperature. The residual weight however differed depending on the solid used for the 
experiment. The higher residual weight obtained for $\mathrm{SiO}_{2}$ suggests the formation of higher wax proportion retained on the solid than using Si-MFI. When Si/AI-MFI is used, a slight shift of the decomposition temperature toward the lower temperature is observed, with a decomposition starting at $400{ }^{\circ} \mathrm{C}$ and ending at $490{ }^{\circ} \mathrm{C}$. Then, the Si/Al-MFI catalyst is able to activate decomposition of $\mathrm{PE}$ at lower temperature than the thermal decomposition temperature. In this case, the maximum mass loss is close to $90 \%$, demonstrating the formation of a very low proportion of residual wax than when pure silicas are used.

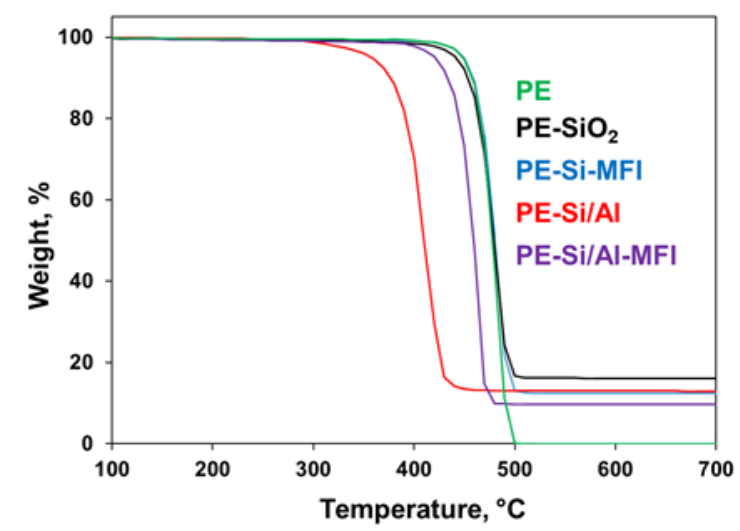

Figure 7. Thermogravimetric analysis for $\mathrm{SiO}_{2}$, Si/Al, Si-MFI and Si/Al-MFI materials and pure $\mathrm{PE}$.

Finally, with Si/Al catalyst, the temperature shift is far more marked than using Si/AI-MFI. The starting decomposition of PE is measured at $300^{\circ} \mathrm{C}$, with the decomposition ending at $460^{\circ} \mathrm{C}$ The residual weight, even if less important than using pure silica sample, remains higher than over Si/Al-MFI. Then $\mathrm{Si} / \mathrm{Al}$ is more prone to form waxy compounds which are not decomposed at high temperatures than Si/Al-MFI. Based on the temperature at which $50 \%$ of $\mathrm{PE}$ is degraded, the following rank can be established: $\mathrm{Si} / \mathrm{Al}>\mathrm{Si} / \mathrm{Al}-\mathrm{MFI}>\mathrm{Si}-\mathrm{MFI} \sim \mathrm{SiO}_{2} \sim$ thermal. The comparison of $\mathrm{Si} / \mathrm{Al}$ and $\mathrm{Si} / \mathrm{Al}-\mathrm{MFI}$ results suggests also that strong acid sites, mainly located in the micropores of the zeolite, are not needed for activating the PE decomposition. Si/AI exhibits a much higher external surface area than Si/Al-MFI $\left(140 \mathrm{~m}^{2} \cdot \mathrm{g}^{-1}\right.$ vs $\left.7 \mathrm{~m}^{2} \cdot \mathrm{g}^{-1}\right)$. Therefore a high external surface area with sufficient concentration of acid sites seems to be adapted to activate the PE decomposition at low temperature [12].

\subsection{Catalytic flash pyrolysis}

Catalyst effect on the phases distribution: Figure 8 presents the distribution in gas, liquid, wax and residue at the end of the flash pyrolysis reaction $\left(40 \mathrm{~min}\right.$ at $450{ }^{\circ} \mathrm{C}$ ). The low activity of pure silica materials ( $\mathrm{Si}-\mathrm{MFI}$ and $\mathrm{SiO}_{2}$ ) is characterized by an incomplete decomposition of $\mathrm{PE}$ (4 wt.\% of residue with $\mathrm{SiO}_{2}$; 23 wt.\% of residue with Si-MFI), and with a consequent formation of wax (31 wt. $\%$ for $\mathrm{SiO}_{2}$ and 29 wt. $\%$ for Si-MFI). The slightly better performances obtained with $\mathrm{SiO}_{2}$ can be explained by its higher total acidity $\left(45 \mu \mathrm{mol} . \mathrm{g}^{-1}\right)$ in comparison with that of the Si-MFI $\left(17 \mu \mathrm{mol} . \mathrm{g}^{-1}\right)$, in addition to its four times higher external surface area. Even when using a catalyst without acidity, a radical-activated mechanism is expected to occur, the pore structure promotion (i.e. a larger surface available for polymer-solid contact) allows to explain the slightly better results obtained with $\mathrm{SiO}_{2}$ [24]. In line with the thermogravimetric study, Si/Al and Si/Al-MFI are the most active catalysts for the PE pyrolysis since in both cases, the PE decomposition is complete and no residue remains at the end of the experiment. Moreover, waxy compounds are not observed when using Si/Al-MFI, while less than $10 \%$ are measured with $\mathrm{Si} / \mathrm{Al}$. those results are consistent with previously discussed TG results. The gas and liquid yields increases then significantly, with liquid yields reaching 35-36 wt.\% with Si/Al and Si/Al-MFI. The significant improvement in liquid+gas yield obtained using the Si-Al containing catalyst is a clear evidence of the need of acidic sites to activate the decomposition of PE, according to a carbenium ion-activated mechanism instead of radical-type mechanism [16]. Similarly to our results, Lin et al. reported that the decomposition of PE using ZSM-5 led to higher gas yield than when silica-alumina catalyst is used [15]. The increase in gas phase proportion observed for Si/AI-MFI can then be related to the presence of strong acid sites, sites that can initiate cracking reactions over heavy compounds.

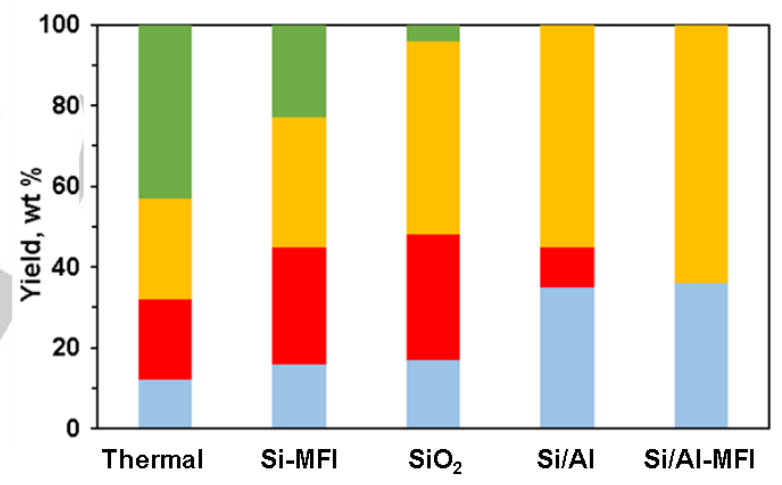

Figure 8. Phase distribution obtained during flash pyrolysis of $P E$ reaction at $450^{\circ} \mathrm{C}$. Blue $=$ liquid, red $=$ wax, yellow $=$ gas, and green $=$ residue.

Catalyst effect on the liquid phase product distribution: The carbon number distribution of the liquid products obtained after flash pyrolysis reaction are shown in Figure 9. Flash thermal pyrolysis results in a distribution of products extending from $\mathrm{C} 3$ to $\mathrm{C} 30$, with heavy products from $\mathrm{C} 10+$ representing $40 \mathrm{wt} . \%$ of the total liquid fraction (C14+ being of $18 \mathrm{wt} . \%)$. The C6-C9 fraction is representing 42 wt.\% and the light fraction (C3-C5) represents only $18 \mathrm{wt} . \%$. The flash catalytic pyrolysis reaction performed in the presence of pure silica samples (Si-MFI and $\mathrm{SiO}_{2}$ ) leads to a significantly different distribution of products. A significant decrease of the heavy fraction $\left(\mathrm{C} 10_{+}\right)$is observed, with only 16-20 wt.\% measured. The highest light product proportion is obtained with the $\mathrm{SiO}_{2}$ catalyst (39 wt.\%) while the Si-MFI leads preferably to the production of intermediate fraction (C6-C9 representing 54 wt.\% of the products). Finally, the proportion of light products (C3-C5) is increasing again when acidic Si/Al catalysts are used, while the residual fraction 
of heavy products $\left(\mathrm{C} 10_{+}\right)$is falling below $3 \mathrm{wt} . \%$ (Si/AI-MFI) or less (Si/AI). Then, with Si/Al-MFI, a C3-C5 proportion representing $55 \mathrm{wt} . \%$ of the liquid fraction is obtained while only $45 \mathrm{wt} . \%$ are obtained with Si/Al. Consequently, as the acidity of the catalyst increases, the total amount of C3-C5 increases, as already observed by Ohkita et al. in the case of PE catalytic cracking [25]. This evolution is also in line with the higher formation of gas fraction since the highest gas fraction is obtained with Si/Al-MFI.

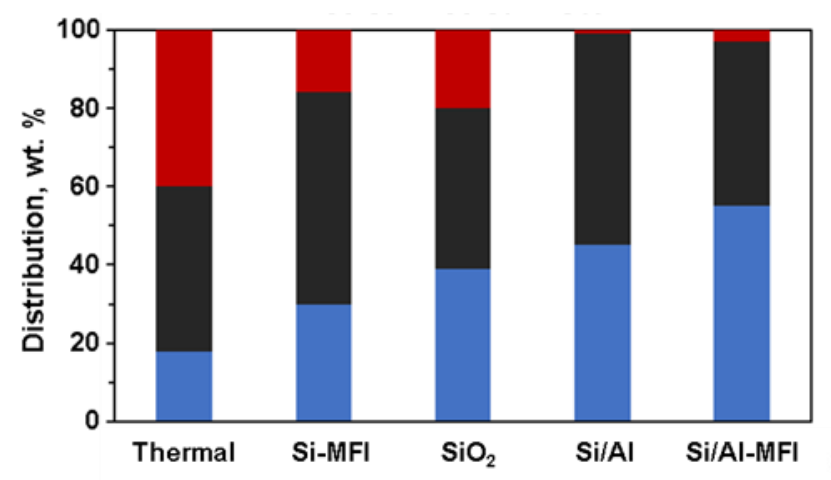

Figure 9. Products distribution of the liquid from the decomposition of $\mathrm{PE}$ at $450^{\circ} \mathrm{C}$. Blue $=\mathrm{C} 3$ to $\mathrm{C} 5$, black $=\mathrm{C} 6$ to $\mathrm{C} 9$, burgundy $=\mathrm{C} 10+$.

Nature of liquid phase products: Figure 10 further details the proportion of paraffins, olefins, cycled hydrocarbons and aromatics obtained after flash pyrolysis reaction. Flash thermal pyrolysis leads to high yields in paraffins (33 wt.\%) and olefins (48 wt.\%). These results are in accordance with other authors [26]. Interestingly, in the conditions of flash catalytic pyrolysis, the presence of both $\mathrm{SiO}_{2}$ and $\mathrm{Si}-\mathrm{MFI}$ allows to promote the cyclization of decomposition products, the crystalline Si-MFI framework leads to a higher proportion of cycled hydrocarbons (34 wt.\%) than with $\mathrm{SiO}_{2}$ (25 wt.\%) while only 6 wt.\% of cyclic molecules are obtained under thermal conditions. Both aluminosilicate catalysts lower the fraction of paraffinic + olefinic compounds when compared to the pure silica counterparts. A significant fraction of aromatics (25 wt.\%) in addition to cycled hydrocarbons (51 wt.\%) is obtained in the presence of Si/AI-MFI.

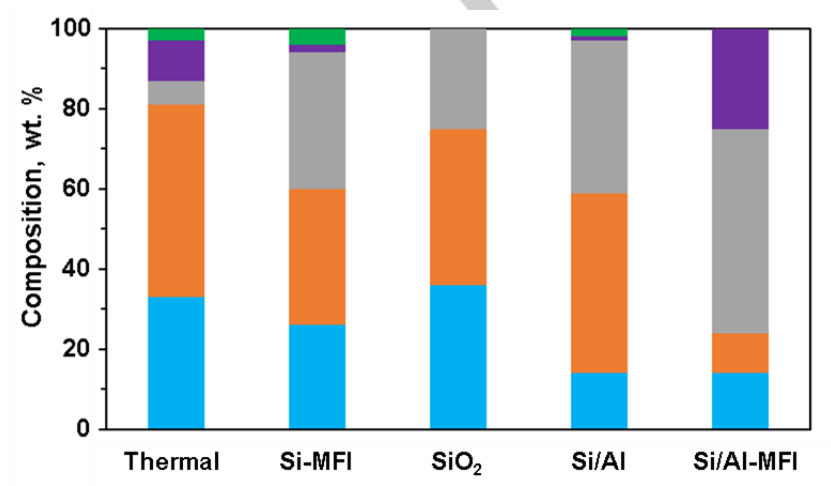

Figure 10. Composition of liquid product from the decomposition of $P E$ at $450^{\circ} \mathrm{C}$. Blue $=$ paraffins, orange $=$ olefins, grey $=$ cycled hydrocarbons, purple $=$ aromatics, and green $=$ others.

On the contrary, Si/Al promotes formation of cycled hydrocarbons (38 wt.\%) and olefins fraction remains consequent (45 wt.\%). As previously mentioned, the primary products issued from the PE cracking forms on the external surface acid sites of the Si/Al and Si/Al-MFI materials. Lin et al also observed the formation of a higher proportion of olefinic C3C7 compounds with Si/Al than with ZSM-5 [17], which is perfectly in line with the presented results. The promotion of aromatization (as BTX [18]) and cyclization observed in the case of Si/AI-MFI (or ZSM-5), when compared to Si/Al can be explained by transformation of primary light products on strong acid sites located in the microporosity. Therefore, while the use of a catalyst of mild acidity is preferred to obtain linear molecule, catalysts with strong acidic sites afford the production of valuable aromatics.

\section{Conclusions}

Different (alumino)silicate catalysts with controlled properties (size, morphology, acidity) were prepared, characterized, and used for the flash catalytic pyrolysis of polyethylene (PE). Based on thermogravimetric analysis, catalytic decomposition of $P E$ is activated in the presence of silica-alumina (amorphous or MFItype) catalyst. Using pure silica containing material (amorphous or MFI-type) did not allows to convert PE at lower temperature than using thermal conditions. These results were confirmed during the flash catalytic pyrolysis of PE experiments, performed at $450{ }^{\circ} \mathrm{C}$. Amorphous $\mathrm{Si} / \mathrm{Al}$ and MFI-type Si/Al containing zeolite are the most efficient catalysts, and they allow the complete decomposition of PE with a limited formation of wax. On the contrary, poorly acidic silicic catalysts present a low decomposition activity, resulting in the formation of a large amount of residue and wax.

The liquid to gas phase distribution is significantly affected by the catalyst acidity, a higher gas phase proportion being obtained when the catalyst acidity increases. In addition, the acidity increase leads to an increase of the light molecule fraction in the liquid phase (C3 to $\mathrm{C5}$ ). From a nature molecule point of view, the strong acidity exhibited by the Si/AI MFI-type zeolite favors the formation of aromatics and cycled hydrocarbons, while the lowest acidity displayed by the amorphous aluminosilicate favors olefins formation.

\section{Experimental Section}

Chemicals: All chemicals were used as purchased: sodium hydroxide (NaOH 98 wt.\%, Alfa Aesar), sodium aluminate $\left(\mathrm{NaAlO}_{2} 98\right.$ wt.\%, Alfa Aesar), Ludox HS40 ( $\mathrm{SiO}_{2} 40$ wt.\%, Aldrich), ammonium nitrate ( $\mathrm{NH}_{4} \mathrm{NO}_{3} 98$ wt.\%, Alfa Aesar), Tetraethylorthosilicate (TEOS 98 wt.\%, Acros), Tetrapromylammonium hydroxide (TPAOH $1 \mathrm{M}$ in water, Sigma), Aluminium isopropoxide $\left(\mathrm{Al}(\mathrm{OiPr})_{3} 98 \mathrm{wt} \%\right.$, Sigma Aldrich), ethanol 
(EtOH 99.9\%, Alfa Aesar), linear low density polyethylene (Eltex® PF6220AE) from Wipak (Bousbecque, France). $\mathrm{SiO}_{2}$ sample was kindly provided from Saint Gobain (SS61138).

Silicalite-1 preparation: A solution composed of $\mathrm{H}_{2} \mathrm{O}$, TEOS and TPAOH is prepared with the following sol composition $100 \mathrm{SiO}_{2}: 400$ EtOH : $40 \mathrm{TPAOH}: 2000 \mathrm{H}_{2} \mathrm{O}$. The mixture was prepared at room temperature and aged for $24 \mathrm{~h}$ under stirring. The $\mathrm{pH}$ was adjusted to 11 by adding 10 wt.\% sodium hydroxide solution. The resulting solution was transferred in a Teflon-lined autoclave and crystallized at $140^{\circ} \mathrm{C}$ for $48 \mathrm{~h}$ under static conditions. The template removal was performed by calcination for $2 \mathrm{~h}$ at $200{ }^{\circ} \mathrm{C}\left(2^{\circ} \mathrm{C} \mathrm{min}-1\right)$, then for $8 \mathrm{~h}$ at $550{ }^{\circ} \mathrm{C}\left(0.5^{\circ} \mathrm{C}\right.$ $\left.\mathrm{min}^{-1}\right)$ under air [11a]. An ion exchange process was carried out in the presence of $0.5 \mathrm{M} \mathrm{NH}_{4} \mathrm{NO}_{3}$, for $12 \mathrm{~h}$ at $70^{\circ} \mathrm{C}$. The ion exchange step is followed by a calcination at $500{ }^{\circ} \mathrm{C}$ for $3 \mathrm{~h}\left(0.5^{\circ} \mathrm{C} \mathrm{min} \mathrm{m}^{-1}\right)$ under air to produce the $\mathrm{H}$-form zeolites. The final sample was denoted Si-MFI.

ZSM-5 preparation. Preparation involves two successive steps. The first step is for seeds synthesis. Seed suspension was prepared from a mixture of sodium hydroxide, $\mathrm{H}_{2} \mathrm{O}$ and TPAOH. After complete dissolution, Ludox is added dropwise and the mixture is stirred for $1 \mathrm{~h}$ at room temperature. Mixture molar composition is $100 \mathrm{SiO}_{2}: 20 \mathrm{Na}_{2} \mathrm{O}$ : 6.6 TPAOH : $4750 \mathrm{H}_{2} \mathrm{O}$. Hydrothermal treatment was performed at $100{ }^{\circ} \mathrm{C}$ for $16 \mathrm{~h}$, and the resulted seeds were kept in solution form. Thereafter, in a second step, a solution composed of $\mathrm{H}_{2} \mathrm{O}$, sodium hydroxide and sodium aluminate is prepared and kept at room temperature under stirring for $1 \mathrm{~h}$. Then the silica precursor is added and the solution is maintained under stirring at room temperature for 1 $\mathrm{h}$, with the following molar composition of $1.87 \mathrm{Al}_{2} \mathrm{O}_{3}: 100 \mathrm{SiO}_{2}: 4$ $\mathrm{Na}_{2} \mathrm{O}: 2500 \mathrm{H}_{2} \mathrm{O}$. Finally, the seed suspension is added dropwise to the reaction mixture without any purification. Hydrothermal treatment was performed at $180^{\circ} \mathrm{C}$ for $40 \mathrm{~h}$ under static conditions. The removal of the organic template was carried by calcination $\left(2 \mathrm{~h}\right.$ at $200^{\circ} \mathrm{C}\left(2^{\circ} \mathrm{C}\right.$ $\left.\mathrm{min}^{-1}\right)$, followed by $8 \mathrm{~h}$ at $550^{\circ} \mathrm{C}\left(0.5^{\circ} \mathrm{C} \mathrm{min}-1\right)$ under air [27]). After the ion exchange process (see preparation of Si-MFI sample), the sample was denoted Si/AI-MFI.

Amorphous aluminosilica sample. The sol composition for the preparation of the amorphous aluminosilica sample was $100 \mathrm{SiO}_{2}: 1150$ $\mathrm{EtOH}: 1000 \mathrm{H}_{2} \mathrm{O}: 6.2 \mathrm{Al}_{2} \mathrm{O}_{3}$, according to the procedure described in [11a]. The sol was aged at $60^{\circ} \mathrm{C}$ for $24 \mathrm{~h}$, then calcined at $550^{\circ} \mathrm{C}$ for 3

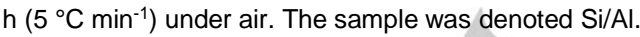

Sample characterization: Sample characterization involves ICP, XRD, $\mathrm{N}_{2}$-physisorption, SEM, DLS particle size measurement, ${ }^{27} \mathrm{Al}$ and proton solid state NMR, $\mathrm{NH}_{3}$-TPD, and ATG study of PE decomposition. X-ray diffraction was performed on a Bruker AXS D8 Advance diffractometer in Bragg-Brentano configuration fitted with a LynxEye Super Speed detector. XRD patterns were recorded with CuKa radiation $(\lambda=0.154$ $\mathrm{nm}, 40 \mathrm{kV}, 30 \mathrm{~mA}$ ) in the $3-60^{\circ} 2 \theta$ range with a $0.02^{\circ} 2 \theta$ step. $\mathrm{N}_{2}$ physisorption isotherms were recorded at $-196{ }^{\circ} \mathrm{C}$ on a Tristar II Plus system from Micromeritics Instruments. Before analysis, the samples were outgassed under dynamic vacuum at $300{ }^{\circ} \mathrm{C}$ for $5 \mathrm{~h}$. The textural properties were determined from the adsorption/desorption isotherms by using the MicroActiveTristar II Plus software version 5.02. The BET surface area was determined using the multipoint BET algorithm in the $\mathrm{P} / \mathrm{P}_{0}$ range of $0.10-0.25$ (criteria: correlation coefficient $>0.998 ; \mathrm{C}$ constant $>0$; Rouquerol transform increases on the selected portion). The t-plot method was applied to quantify the micropore volume and surface area (de Boer statistical thickness of 3.8-6.5 $\AA$ ). Scanning Electron Microscopy analysis was performed on a JEOL JSM-7800F LV instrument equipped with a FEG source. Prior to the analysis, the samples were metalized with a layer of $180 \mathrm{~nm}$ of chromium. The particle size was measured by using ImageJ software. The average hydrodynamic diameters of calcined materials were determined by Dynamic Light Scattering (DLS, Nano ZS from Malvern Instruments). DLS was applied with an angle of 173 by using He-Ne laser $(4 \mathrm{~mW})$ operated at $633 \mathrm{~nm}$. For the analysis, the materials were dispersed in water under ultrasound $(3 \mathrm{~min}) .{ }^{27} \mathrm{Al}$ MAS-NMR experiments were performed at $208.5 \mathrm{MHz}$ on an AVANCE III 18.8T spectrometer equipped with a $3.2 \mathrm{~mm}$ probe head operating at spinning frequencies of $20-22 \mathrm{kHz}$. The quantitative spectra were acquired with a $1 \mu$ s pulse length, 512 transients and a recycle delay of $0.5 \mathrm{~s}$. The ${ }^{[x]} \mathrm{Al}$ quantification was directly obtained by signal integration. The $2 \mathrm{D}{ }^{27} \mathrm{Al} /{ }^{1} \mathrm{H}$ map was obtained with the Dipolar-Heteronuclear Multiple- Quantum Correlation NMR technique (D-HMQC) [28]. The $4096 \times 120$ acquisition points were recorded with a SR $4{ }^{2}{ }_{1}$ recoupling scheme of $200 \mu \mathrm{s}$. Each slice was acquired with 192 transients and a recycle delay of $1 \mathrm{~s}$. Temperatureprogrammed $\mathrm{NH}_{3}$ desorption ( $\mathrm{NH}_{3}$-TPD) experiments were carried out on a Micromeritics Autochem II 2920 chemisorption analyser instrument. Ammonia concentration in the outlet mixture was monitored using an OmnistarTM Pfeiffer mass spectrometer. Prior to the desorption, the samples were outgassed under helium at $200{ }^{\circ} \mathrm{C}\left(60 \mathrm{~min}, 10^{\circ} \mathrm{C} \mathrm{min}-1\right)$. Sample saturation is performed under $10 \% \mathrm{NH}_{3}$ in $\mathrm{He}\left(30 \mathrm{~mL} \mathrm{~min}^{-1}\right)$ at $100{ }^{\circ} \mathrm{C}\left(130^{\circ} \mathrm{C}\right.$ for Si/Al-MFI sample) for $30 \mathrm{~min}$. The desorption experiment was performed with a ramp of $10^{\circ} \mathrm{C} \mathrm{min}{ }^{-1}$ from $100{ }^{\circ} \mathrm{C}$ to $700^{\circ} \mathrm{C}$. ATG measurements of PE decomposition were carried out on a SDT Q600 TA instrument. The experiments were performed under a $\mathrm{N}_{2}$ flow of $100 \mathrm{~mL} \mathrm{~min}^{-1}$ applying a temperature ramp of $10^{\circ} \mathrm{C} \mathrm{min}{ }^{-1}$ up to $900^{\circ} \mathrm{C}$. The catalyst loading is fixed at $10 \mathrm{wt} . \%$.

Flash (Catalytic) Pyrolysis tests: thermal and catalytic pyrolysis reactions of $\mathrm{PE}$ were carried out in a pyrolysis pilot composed of a homemade reactor, a furnace (CARBOLITE CERGO $30-3000^{\circ} \mathrm{C}$ ) and a liquid condensation system. The reactor is described in Figure 12. It is composed of a stainless steel tube (length of $700 \mathrm{~mm}$, diameter of 60.3 $\mathrm{mm}$ ). Catalyst weight (10 wt.\%) was mixed with the PE and placed in the cooling coil coupled to a chiller (LAUDA ECO SILVER) where the temperature was controlled at $20 \pm 1^{\circ} \mathrm{C}$. The reactor was then purged under nitrogen ( 5 L. $\left.\mathrm{min}^{-1}\right)$ for $5 \mathrm{~min}$, and the flow was stabilized at 200 $\mathrm{mL} \cdot \mathrm{min}^{-1}$. Flash pyrolysis was carried out by introducing the sample in the heated zone after temperature stabilization at the reaction temperature. As the pyrolysis can lead to the formation of a liquid phase, a gas phase and a solid residue, the liquid phase composed of condensable molecules was recovered in two baths of liquid nitrogen and the residue remains in the sample holder. Wax product can also be produced, and recovered at the exit of the reactor. At the end of the experiment, liquid, solid and wax were quantified. The gas molecule yield was calculated by subtracting the liquid/wax and residue amount from the initial polymer weight.

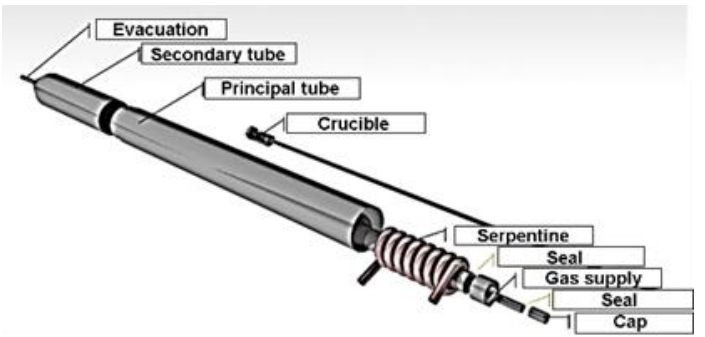

Figure 12. Scheme of the pyrolysis pilot

Table 3. GC protocol applied for liquid phase analysis

$$
\text { GC-MS GC-FID }
$$




\begin{tabular}{lll}
\hline Carrier gas & $\mathrm{He}$ & $\mathrm{N} 2$ \\
\hline Carrier gas flow & $24.2 \mathrm{~mL} \mathrm{~min}-1$ & $14.3 \mathrm{~mL} \mathrm{~min}-1$ \\
\hline Initial temperature/ initial time & $40^{\circ} \mathrm{C}$ & $40^{\circ} \mathrm{C}$ \\
\hline Heating rate & $8{ }^{\circ} \mathrm{C} \mathrm{min}-1$ & $8{ }^{\circ} \mathrm{C} \mathrm{min}-1$ \\
\hline Final temperature/ final time & $280^{\circ} \mathrm{C}$ & $280^{\circ} \mathrm{C}$ \\
\hline Injection temperature & $300^{\circ} \mathrm{C}$ & $300^{\circ} \mathrm{C}$ \\
\hline Split flow & $20 \mathrm{~mL} \mathrm{~min}-1$ & $10 \mathrm{~mL} \mathrm{~min}-1$ \\
\hline Transfer line & $300^{\circ} \mathrm{C}$ & - \\
\hline
\end{tabular}

[5] a) U. Arena, M. Mastellone, F. Perugini, Int. J. Life Cycle Assess. 2003, 8, 92-98; b) J.A. Onwudili, N. Insura, P.T. Williams, J Anal Appl Pyrol 2009, 86, 293-303.

[6] a) W. Kaminsky, B. Schlesselmann, C.M. Simon, Polym Degrad Stabil, 1996, 53, 189-97; b) J.A. Marsh, C.Y. Cha, F.D. Guffey, Chem.Engin. Commun., 1994, 129, 69-78.

[7] A. Karaduman, J. Energ. Sources, 2002, 24(7), 667-674; b) P.T. Williams, E. A. Williams, Environ. Technol., 1999, 20(11), 1109-1118.

[8] I. Ahmad, M.I. Khan, H. Khan, M. Ishaq, R. Tariq, K. Gul, W.Ahmad, Int J Green Energy, 2015, 12(7), 663-671.

[9] a) J.P.-Pariente, T. Álvaro-Mõnoz, J. Garcia Martnez, K. Li, M.E. Davis Mesoporous Zeolites. Preparation, Characterization and Applications, Wiley-VCH, 2015, pp 259-289; b) L. Shirazi, E. Jamshidi, M.R. Ghasemi, Cryst. Res. Technol. 2008, 43(12), 1300-1306; c) K.A. Taracha, K. Góra-Mareka, J. Martinez-Triguero, I. Melián-Cabrera, Catal Sci Technol, 2017, 7, 858-873; d) M. Rutkowska, D. Macina, Z. Piwowarska, M. Gajewska, U. Díazc, L. Chmielarza, Catal. Sci. Technol, 2016, 6, 4849.

Liquid phase analysis was performed by GC-MS using a shimadzu GC2010 coupled to a Shimadzu GC-MS-QP2010 plus mass spectrometer. The GC column is a $30 \mathrm{~m}^{*} 0.25 \mu \mathrm{m}^{\star} 0.25 \mu \mathrm{m}$ optima- $5 \mathrm{~ms}$ capillary column. In addition, the oil was separately analysed for quantification using GC201 Shimadzu equipped with an FID detector and a $30^{*} 0.32 \mathrm{~mm} 0.25$ $\mu \mathrm{m}$ Zebron ZB-5 capillary column for separation. The protocols applied are detailed in Table 3.

\section{Acknowledgements}

This work is part of the PYROCAT project co-financed by the European Union with the European Regional Development Fund (ERDF). Chevreul Institute (FR 2638), Ministère de l'Enseignement Supérieur et de la Recherche and Région Hauts-de-France are also acknowledged for supporting this work. The authors acknowledge Sophie Heymans from NeoEco Development for her participation to the work. The authors thank Olivier Gardoll, Laurence Burylo and Alexandre Fadel for their contribution in $\mathrm{NH}_{3}-\mathrm{TPD}, \mathrm{XRD}$ and SEM analysis, respectively.

Keywords: aluminosilica $•$ zeolite $•$ flash catalytic pyrolysis $•$ polyethylene

[1] a) S.M. Al-Salem, A. Antelava, A. Constantinou, G. Manos, A. Dutta, J Environ Manage, 2017, 197, 177-198; b) R. Miandad, M.A. Barakat, A.S. Aburiazaiz, M.Rehan, A.S. Nizami, Process Saf Environ, 2016, 102, 822-838.

[2] a) J.H. Clark, J. Aguado, D.Serrano, Feedstock recycling of plastic waste, Editor: J.H. Clark, RSC Clean Technology Monographs, Cambridge, 1999, pp 13-28; b) S. Honus, S. Kumagai, G. Fedorko, V. Molnár, T.Yoshioka, Fuel, 2018, 221, 346-360; c) M.A. Hazrat, M.G. Rasul, M.M.K. Khan, Procedia Engineering, 2015, 105, 865-876; d) C.J. Rhodes, Sci Prog. 2018, 101(3), 207-260.

[3] P.T. Williams, Waste Manage, 2013, 33, 1714-1728.

[4] a) M. Rehan, R. Miandad, M.A. Barakat, I.M.I. Ismail, T. Almeelbi, J. Gardy, A. Hassanpour, M.Z. Khan, A. Demirbas, A.S. Nizami, Int Biodeter Biodegr, 2017, 119, 162-175; b) D.S. Achilias, C. Roupakias, P. Megalokonomos, A.A. Lappas, E.V. Antonakou, J Hazard. Mater., 2007, 149, 536-542 ; c) P. Carniti, A. Gervasini, S. Bernardelli, Polym Degrad Stabil, 1997, 57, 301-306; d) P. Carniti, P. L. Beltrame, A. Gervasini, A. Castelli, L. Bergamasco, J Anal Appl Pyrol, 1997, 40-41, 553-568.

[10] a) M. Choi, K. Na, J. Kim, Y. Sakamoto, O. Terasaki, R. Ryoo, Nature 2009, 461, 246-249. b) M. Tawalbeh, F. H. Tezel, S. Letaief, C Detellier., Separ Sci Technol, 2012, 47(11), 1606-1616; c) H. Chen, X. Zhang, J. Zhang, Q. Wang, RSC Adv., 2017, 7, 46109- 46117.

[11] a) A. Ishihara, H. Negura, T. Hashimoto, H. Nasu, Appl.Catal A-Gen, 2010, 388, 68-76; b) J.R. Kim, J.H. Yoon, D.W. Park, Polym Degrad Stabil, 2002, 76, 61-67; c) N. Kubicek, F. Vaudry, B.H. Chiche, P. Hudec, F. Di Renzo, P. Schulz, F. Fajula, Appl Catal A-Gen, 1998 175(1) 159-171

[12] J. Aguado, D. P. Serrano, G. S. Miguel, J. M. Escola, and J. M. Rodríguez, J Anal Appl Pyrol 2007, 78(1), 153-61.

[13] J. Qi, T. Zhao, X. Xu, F. LI, J. Porous Mater, 2011, 18, 509-515.

[14] a) P.S. Utama, E. Saputra, Khairat, lop Conf Ser-Mat Sci, 2018, 345 012009 ; b) R.E. Morsi, R.S. Mohamed, R Soc Open Sci, 2018, 5 172021-172036.

[15] Y.H. Lin, M.H. Yang, T.F. Yeh, M.D. Ger, Polym Degrad Stabil, 2004 86(1), 121-128.

[16] A. Marcilla, M. I. Beltrán, F. Hernandez, R. Navarro, Appl Catal A-Gen 2004, 278, 37-43.

[17] Y.H. Lin and M. H. Yang, J Anal Appl Pyrol, 2008, 83(1), 101-109.

[18] D.W. Park, E.Y. Hwang, J R. Kim, J.K. Choi, Y.A. Kim, and H.C. Woo, Polym Degrad Stabil, 1999, 65, 3-8. S

[19] A. Matayeva, F. Basile, F. Cavani, D. Bianchi, S. Chiaberge, Stud Surf Sci Catal 2019, 178, 231-256.

[20] G. Wu, W. Wu, X. Wang, W. Zan, W. Wang, C. Li, Microp Mesop Mater, 2013, 180, 187-195.

[21] M. Zhou, A.A. Rownaghia, J. Hedlund, RSC Adv., 2013, 3, 15596 15599.

[22] a) E. Lippmaa, A. Samoson, M. Magi, J Am Chem Soc, 1986, 108(8), 1730-1735; b) M. Taoufik, K.C. Szeto, N. Merle, I.D. Rosal, L. Maron, J. Trebosc, G. Tricot, R. Gauvin, L. Delevoye, Chem Eur J, 2014, 20 4038-4046.

[23] a) P. Arudra, T.I. Bhuiyan, M.N. Akhatar, A.M. Aitani, S.S Al-Khattaf, H. Hattori, ACS Catal, 2014, 4, 4205-4214;

[24] Y. Sakata, A. Uddin, A. Muto, J Anal Appl Pyrol, 1999, 51, 135-155.

[25] H. Ohkita, R. Nishiyama, Y. Tochihara, T. Mizushima, N. Kakuta, Y. Morioka, A. Ueno, Y. Namiki, S. Tanifuji, H. Katoh, H. Sunazuka, R.Nakayama, T. Kuroyanagi, Ing Eng Chem Res, 1993, 32, 3112-3116.

[26] A. Marcilla, M. I. Beltrán, and R. Navarro, Appl Catal B-Environ, 2009, 86(1-2), 78-86.

[27] H. Lechert, R. Kleinwort, Verified synthesis of zeolitic materials, 2016, pp 284

[28] G. Tricot, J. Trebosc, F. Pourpoint, R. Gauvin, L. Delevoye, Annual Reports on NMR Spectroscopy, 2014, 81, 145-18. 
Entry for the Table of Contents (Please choose one layout)

Layout 1:

\section{FULL PAPER}

A series of amorphous and crystalline (alumino)silicate catalysts, with variable acidity, are evaluated for the flash pyrolysis of polyethylene (PE).

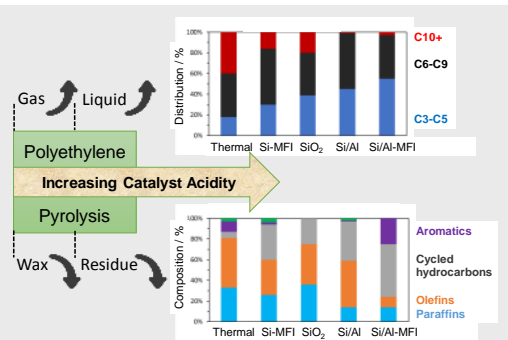

Sophie Klaimy, Carmen Ciotonea, Jérémy Dhainaut, Sébastien Royer, Mathilde Casetta, Sophie Duquesne, Grégory Tricot and Jean-François Lamonier*

Page No. - Page No.

Flash catalytic pyrolysis of polyethylene over (alumino)silicate materials

Layout 2:

\section{FULL PAPER}

((Insert TOC Graphic here; max. width: $11.5 \mathrm{~cm}$; max. height: $2.5 \mathrm{~cm}$ ))

Author(s), Corresponding Author(s)*

Page No. - Page No.

Title

Text for Table of Contents 